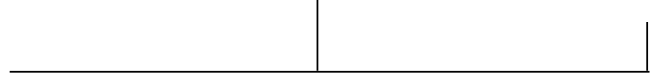

Rev. Latinoam. Psicopat. Fund., São Paulo, v. 12, n. 4, p. 677-697, dezembro 2009

\title{
Quem tem medo do lobo mau? Juventude, agressividade e violência*
}

\author{
Ana Cleide Guedes Moreira \\ Junia de Vilhena \\ Alexandre Theo de Almeida Cruz \\ Joana de Vilhena Novaes
}

\begin{abstract}
Discute-se a dinâmica da agressividade e da violência e o papel que a cultura brasileira desempenha no tocante à nossa juventude. Utilizamos Freud e suas postulações sobre a violência e Winnicott, sublinhando as diferenças entre a agressividade e a tendência antissocial que pode vir a desembocar na violência destrutiva da delinquência. Amparados no conceito de que a mãe ambiente está ancorada na cultura, discutimos finalmente o lugar desses jovens em nossa sociedade.
\end{abstract}

Palavras-chave: Agressividade, violência, juventude, exclusão social, tendência antissocial

* Este artigo é uma versão expandida do trabalho apresentado no III Congresso Internacional de Psicopatologia Fundamental e IX Congresso de Psicopatologia Fundamental, realizado em setembro de 2008 na Universidade Federal Fluminense - UFF, Niterói, RJ, Brasil.

Pesquisa financiada pela Coordenação de Aperfeiçoamento de Pessoal de Nível Superior - CAPES, através do Programa Nacional de Cooperação Acadêmica - PROCAD (Brasília, DF, Brasil) 


\section{Introdução}

Crianças, menores, pivetes ou trombadinhas? Quem são essas crianças que tanto nos incomodam e que fingimos não ver nos sinais das ruas ao trancarmos as escuras janelas de nossos automóveis? Delinquentes, traficantes e marginais - quem são esses jovens assim nomeados, que tanto medo nos causam e a quem, frequentemente, fechamos os olhos, quando não justificamos suas mortes tão violentas?

Dentre os temas atuais que mais têm gerado polêmica, e mesmo grande comoção social, estão a agressividade e a violência dirigidas contra as gerações mais jovens da sociedade brasileira ou cometidas por estes mesmos jovens. A contínua apresentação na mídia de adolescentes que praticam infrações violentas e, o reverso da moeda, os que sofrem maus-tratos físicos e psicológicos cometidos muitas vezes por seus próprios familiares, ou pelas instituições socioeducativas do Estado, na terrível violência urbana nas grandes cidades brasileiras, demonstra como o tema se encontra na ordem do dia.

Neste trabalho buscamos discutir a dinâmica da agressividade e da violência, posto que fazemos uma distinção entre ambas e o papel que a cultura brasileira desempenha no tocante à nossa juventude. Para tal, recorremos inicialmente a Freud e suas postulações sobre a violência e a agressividade, em suas origens pulsionais, psíquicas, mas também superegoicas, ou seja, históricas e culturais. Da ciência política, a trama dos conceitos de violência e poder de Estado é brevemente revisitada, para situar a concepção freudiana de violência no pensamento ocidental.

Em um segundo momento, recorrendo à teoria winnicottiana, buscamos apontar as diferenças entre a agressividade que cria e a tendência antissocial que pode vir a desembocar na violência destrutiva da delinquência.

Finalmente, colocando-se em questão o conceito freudiano de pulsão de morte em suas relações com a agressividade e violência, 
desde sua invenção freudiana, busca-se percorrer seu estatuto de polêmica na literatura psicanalítica, sob dois fios condutores: as análises kleinianas e laplancheanas.

À guisa de conclusão, fundada no conceito de que a mãe ambiente está ancorada na cultura, discutimos finalmente o lugar desses jovens em nossa sociedade.

\section{Freud e os destinos da agressividade}

Em meados do século passado, Einstein escreveu a Freud pedindo-lhe que se pronunciasse a respeito da atitude agressiva do homem. Freud (1933[1932]) respondeu-lhe com o artigo "Por que a guerra?" fazendo a seguinte referência à questão da violência: “(...) é pois um princípio geral que os conflitos de interesses entre os homens são resolvidos pelo uso da violência. É isto que se passa em todo o reino animal, do qual o homem não tem motivos para se excluir" (p. 198).

No decorrer de sua carta, Freud apresenta as razões por que afirma que os conflitos de interesses, em geral, são resolvidos pelo uso da violência. Relembrando "Totem e tabu" (1913), Freud assinala que inicialmente um indivíduo dominava o grupo pela força muscular, depois por instrumentos. Mesmo com a superioridade intelectual, o objetivo final de toda a luta era que o adversário fosse subjugado ou destruído. Com o transcurso da história, o uso do poder pelo indivíduo mais forte pôde ser feito através das leis, não sem atravessar a violência da horda primitiva contra o pai - o Urvater - cuja consequência é instalar a interdição nas pulsões sexuais e de morte, marcando o sujeito com a proibição do incesto e do parricídio, assim gerando, consequentemente, a cultura e a civilização. A união de grupos de pessoas podia garantir a manutenção de uma comunidade, mas, mesmo assim, a violência sempre seria o pano de fundo dessa manutenção (cf. Freud, 1933[1932]).

Muitas das ideias contidas em "Por que a guerra?" (1933[1932]) haviam sido analisadas longamente três anos antes em "O mal-estar na civilização" (1930[1929]); nesta obra, Freud analisou a agressividade na cultura, que resulta no que ele chamou de mal-estar, algo que, em geral, todos sentimos cotidianamente, mas é, para Freud, expressão da culpa que segue ao parricídio.

A contradição básica que Freud apresenta e que justifica o mal-estar na civilização é que o princípio do prazer domina o funcionamento do aparelho psíquico desde o início de sua construção de modo eficaz, mesmo estando em desacordo com a cultura e, por essa razão, permanentemente sendo contido pelos efeitos da repressão. Entre a busca do prazer e a repressão, eis como se cons- 
titui sujeito o pequeno bebê humano. Ou dito de outra forma, como se sujeita, no sentido etimológico do termo.

Se a violência sempre esteve presente na história das civilizações é necessário distinguir o que nela é específico da contemporaneidade e, mais precisamente, na sociedade brasileira. Qual o papel da cultura em seu interjogo com a dinâmica pulsional, se cremos, com Freud (1930), que a civilização deve envidar esforços supremos "a fim de estabelecer limites para os instintos agressivos do homem" (p. 117).

Ninguém melhor do que Freud descreveu o que seria uma sociedade sem leis, sem pactos e sem renúncias: pânico, terror, mortes e destruições. Se a lei tem de ser dura e temida para ser respeitada, para ser incorporada simbolicamente, esta tem que estar submetida primeiro ao amor e à justiça. Nenhuma tirania é capaz de anular completamente o desejo, mas nesse lugar onde o horror ocupa o lugar da lei é difícil falar de cidadania.

Vemos, assim, que a lei é a força de uma comunidade. Ainda é violência, pronta a se voltar contra qualquer indivíduo que se lhe oponha; funciona pelos mesmos métodos e persegue os mesmos objetivos. A única diferença real reside no fato de que aquilo que prevalece não é mais a violência de um indivíduo mas a violência de uma comunidade... (Freud, [1933]1932, p. 247)

Nesse momento, a violência é posta a serviço da preservação da comunidade e da vida cultural e não de um suposto desejo instintivo de matar ou fazer sofrer o semelhante. No reino da pura força o que talvez possa ser apreendido como um laço social é o medo da morte, a pura luta para sobreviver - não viver, pois existe uma diferença fundamental. Viver diz respeito ao desejo, enquanto sobreviver restringe-se à necessidade. Daquele que apenas sobrevive só podemos dizer, como Hanna Arendt $(1973,1991)$, que ele é muito triste, pois os homens, embora devam morrer, não nascem para morrer mas para começar.

$\mathrm{O}$ argumento que faz da agressividade instintiva, do "componente animal no homem", a causa da violência baseia-se numa redundância do tipo "o homem comporta-se como um animal porque é um animal". Como bem afirma Hanna Arendt (1973):

(...) para saber que o povo lutará por sua pátria não precisamos descobrir instintos de territorialismo nas formigas, peixes e macacos; para aprender que a superpopulação resulta em irritação e agressividade, não temos que fazer experiências com ratos. Basta passar um dia nos cortiços das grandes cidades (...) (p. 139)

$\mathrm{O}$ argumento biológico sobre a natureza da violência é inconsistente porque baseia-se na questionável premissa de que a violência é produto da conduta humana movida pelo instinto e não pela razão - daí o lugar-comum de que a vio- 
lência é "irracional" ou "emocional". Mas como então justificar a violência premeditada? Nestes casos não só é impossível creditar a violência ao excesso de "emotividade" como é impossível dissociá-la da razão. O ato calculado de violência não dispensa a razão - ao contrário, solicita-a.

A irracionalidade da conduta violenta deve-se ao fato de que a razão desconhece os móveis verdadeiros de suas intenções e finalidades. Ela é irracional quando e porque se dirige a objetos substitutivos, na acepção psicanalítica. Ao contrário do animal que não "deseja" - necessita, a violência humana porta a marca de um desejo.

É porque o sujeito violentado (ou o observador externo) percebe no sujeito violentador o desejo de destruição (desejo de morte, de fazer sofrer) que a ação agressiva ganha o significado de ação violenta. Não existe violência sem desejo de destruição. A violência definida como agressividade e equiparada a um impulso instintivo termina por ser trivializada.

Essa banalização da violência é, talvez, um dos aliados mais fortes de sua perpetuação. A resignação de que somos "instintivamente violentos" faz com que o homem se curve a uma inexorabilidade igual à da morte. Faz dela seu "destino biológico" ou o princípio e o fim de seu destino psíquico, social ou cultural.

Maquiavel já nos apontava o terror dessa situação: onde não se cria um novo território para a existência humana, onde o homem comum não mais se reconhece e se vê reconhecido em sua cidadania, a grande maioria continua a conviver e a agir "normalmente" demonstrando pelo silêncio, pelo medo, pela violência ou pelo cinismo a incapacidade da ética em evitar a irrupção da barbárie.

Em 1651, Thomas Hobbes, um dos pais da concepção moderna de Estado, escreveu, no Leviatã, "Covenants without the sword are but words". Ou seja, os acordos, os pactos sem espadas são meras palavras. É a igualdade do medo, resultante da idêntica capacidade de matar que todos possuem, que persuade os homens, em estado natural, a se unirem em comunidades. Segundo Marx Weber (2004) o Estado seria o domínio do homem pelo meio da violência legítima, isto é, supostamente legítima.

Conforme aponta Pinheiro (1984) o Estado, constitucional ou autoritário, qualquer que seja a forma de governo, segrega permanentemente um regime de exceção: "O mais democrático dos Estados é sempre regime de exceção para enormes contingentes. Loucos, prisioneiros, prostitutas, aidéticos, travestis, negros, homossexuais, crianças, operários irão nascer e morrer sem terem conhecido o comedimento do Leviatã" (p. 193).

Contudo, como aponta Norbert Elias (1994), essa face da violência tem uma contrapartida do Estado, qual seja, a possibilidade de construção da segurança e do bem-estar da população - o chamado Welfare State do século XX. O ponto 
crucial estaria no equilíbrio destas duas funções do Estado, garantindo a pacificação interna.

Ocorre que nenhuma pacificação imposta pelo regime da violência é completa - é uma falsa pacificação. Segundo Poulantzas (1981), em suas reflexões sobre lei e terror, a cisão entre lei e violência é falsa, uma vez que o Estado detém o monopólio legal da ilegalidade da violência física que persiste: "A legalidade do Estado não esvazia o terror. A legalidade corresponde à ilegalidade como sombra irrenunciável (...)" (p. 85).

Para Poulantzas a lei é o código da violência pública organizada e, frequentemente, o Estado age transgredindo a lei, desviando-se dela e transgredindo-a, pois sempre existirá um conjunto de práticas e técnicas estatais que escapam à sistematização e à ordem jurídica. A ilegalidade é frequentemente parte da lei, segue o autor, mesmo quando separadas e distintas fazem parte de uma única estrutura institucional.

É o soberano aquele que decide a exceção, afirma Schmidt (apud Pinheiro, op. cit). E não há instituição mais adequada para verificar esses difíceis limites da legalidade do que o aparelho policial. Segundo Benjamin (1978) "a lei da polícia realmente marca o ponto no qual o Estado, seja por impotência ou por causa das conexões imanentes com qualquer sistema legal, não pode mais garantir por meio de sistemas legais seus fins - no quadro do monopólio legal da violência que o Estado pretenda assegurar (...)" (p. 287).

Se estamos certos até aqui, a concepção freudiana de violência e de estabelecimento da lei como instauradora da cultura e de suas instituições se mantém intacta, pelo menos nesses autores que estão, sem dúvida, entre os mais significativos do pensamento político ocidental. Aquilo que talvez se deve acrescentar àquela concepção é a dupla face da lei, que comporta em si seu contrário, a ilegalidade como sua contraface e, portanto, dimensão constitutiva.

\section{O caso brasileiro}

A observação do caso brasileiro permite compreender melhor alguns dos aspectos aqui enunciados. A legalidade do aumento da repressão chamada política implicou uma contrapartida de maior ilegalidade no funcionamento da repressão ao conjunto da população chamada de "exceção". As "classes torturáveis", ou seja, os miseráveis, pobres, indigentes e minorias que nunca deixaram de viver em regime de exceção, sempre submetidos a uma maior ilegalidade do que aquela normalmente presente na aplicação da lei ou das práticas policiais. 
E isso de longa data. A investigação da ciência política brasileira tem indicado, entre outras análises e teses profícuas, que a violência no Brasil, a criminalidade e a crise do sistema de justiça criminal devem ser encaradas como movimentos sociais e políticos, que espelham sua origem em uma permanência histórico-social de longa duração. Para Gislene Neder (2009), tais movimentos desnudam a manifestação do conflito social e político mais amplo presente na sociedade brasileira, encarnando, na forma e no conteúdo, o sintoma desse conflito. Em suas palavras:

Pensamos que nos casos considerados para análise o processo de legitimação da violência no sistema penitenciário brasileiro está ancorado, na forma e no lugar, com a cultura jurídica e religiosa e os atos violentos são eles próprios derivados de um estoque de tradições de punição ancorados em penas muito antigas (degredo e morte). Portanto, a violência e a crueldade presentes no sistema não são um fato excepcional, mas um acontecimento maior que tem vínculos com a cultura jurídica e a cultura religiosa sobre punição. (p. 29)

É a população mais pobre a que mais vive sob o regime do terror. Sem a contrapartida do Welfare State, sem acesso a um mínimo de cidadania, vivem à margem da sociedade. Marginais, muitas vezes delinquentes, sem dúvida, mas também os que mais vivenciam o registro da violência. Violência, porque a lei que lhes é imposta não tem nenhuma equivalência simbólica. E não a tem porque é sintoma apenas. Sintoma do conflito social brasileiro, em sua transição para a modernidade do assalariamento, realizada penosamente pelas massas de ex-escravos, desde o século XIX.

Os processos psíquicos e psicossociais que levam à repressão da agressividade, seguindo a formulação freudiana, emergem, na subjetividade, como movimento de fuga para o próprio narcisismo. Este se expressaria na formação de grupos "pretensamente homogêneos", acreditando-se coesos e sob a vigência de um desejo de proteção em uma "interioridade" grupal impossível. Por exemplo, na adolescência média, os garotos e garotas tendem a se reunir em bandos e sair por aí, reunindo-se em shoppings, em cybercafés, nos grandes centros urbanos. Nas periferias eles se reúnem nos bailes funks, nas lan houses ou nas igrejas, sobretudo as neopentecostais. No interior do país, isso ainda acontece nas praças centrais das cidades.

$\mathrm{Na}$ adolescência, trata-se de um movimento psíquico em que o eu seria pleno e onipotente, coibindo e reagindo a qualquer mínima diferença; os carecas odiando os punks, por exemplo, geram violência, em um caldo de ódio, rejeição, mal- estar, autorizando-se a exclusão e eliminação do diferente, provocando a sua expulsão da cidade, como forma de evitação e anulação das possíveis experiências de conflitos. Ampliaremos o comentário sobre o narcisismo mais adiante, pois 
se trata sempre do conflito entre o eu e os ideais da cultura cuja importância deve ser ressaltada precisamente no caso da delinquência.

Contudo, se a tese freudiana é verdadeira, e assim o podemos constatar todos os dias em nosso país, é vão o trabalho da civilização, quando com ela também se expandem, a passos largos, o crime organizado, a corrupção ativa, o narcotráfico, o mercado de escravos e escravas humanos para a exploração do trabalho e de sua atividade sexual, bem como outras tantas mazelas que a Justiça, enquanto poder de Estado, tem sido tão insuficiente para conter. Ou, indo mais adiante, quando o crime depende de quem o comete com o aval da própria Justiça. Como aponta Endo (2005):

(...) a desigualdade cotidianamente ratificada tem como consequência imediata a construção de uma malha que articula e desdobra novas formas de violência que, por sua vez, se colocam a serviço da manutenção das desigualdades (...) é quando a violência encontra apoio e suporte em todos os setores da sociedade, que a alimentam e a mantêm como dispositivo aceitável e mesmo desejável. (p. 26)

Finalmente, o caso brasileiro pode ter uma determinação recente, que talvez não escape a muitos, mas é pouco debatida, pelo menos nos meios psicanalíticos. Para Neder, na conjuntura de saída da ditadura, verifica-se que, ao lado de uma crise econômica profunda e prolongada, há um grande desgaste e deslegitimação das estruturas de poder e suas instituições, ao lado do crescimento do crime organizado. Examinando as dimensões internacionais dessa crise, cujas expressões vão desde uma crise de identidade étnico-nacional, do socialismo real, culminada com a queda do Muro de Berlim até o deslocamento do eixo das estratégias militares norte-americanas para o combate ao tráfico internacional de drogas, Neder (2009) afirma que o Brasil passou a ser a rota alternativa, o que também permite especular sobre o destino da indústria armamentista (p. 24).

Pensamos que a tese freudiana permanece intacta no caso brasileiro: o mal-estar em nossa cultura se expressa não só na violência e na crueldade crescentes, parricídios impunes grassando no movimento psíquico nacional, mas também o sofrimento psíquico que escutamos em nossos programas de atendimento comunitário revelam o absurdo do real, posto à prova por sua análise aqui pretendida.

\section{Violência e pathos}

Os compromissos com a cultura levam o homem a ter contato com o sofrimento e este, segundo Freud (1930), ameaça-o a partir de três fontes: do próprio corpo, do mundo externo e dos relacionamentos com os homens (p. 85). É 
do sofrimento que advém das relações sociais que devemos nos ocupar agora para pensar nossa problemática.

Como afirmou em uma peça de teatro célebre o filósofo Sartre: "o inferno são os outros". Esta última fonte de sofrimento é, talvez, a mais penosa de todas, pois ao se constatar no outro uma agressividade que lhe é constitutiva, o que fazer de Eros, que busca ligar, unir, juntar e vai acabar juntando os iguais pela exclusão imediata e subjetiva dos diferentes? Do familiar ao estranho há mais do que um jeito de corpo, um dar de ombros, há um movimento psíquico largamente inconsciente de produção da exclusão do inquietante que até há pouco era tido como um "irmão", ou um "mano". Aceitar uma agressividade constitutiva da subjetividade não é, portanto, algo simples e fácil, e pode parecer um absurdo ter de se admitir tal verdade.

Com efeito, para Freud a agressividade compõe o psiquismo e é manifestação da pulsão de morte, contraposta à pulsão sexual, ambas exigindo um arranjo subjetivo entre o eu e o supereu, o qual tem que dar conta do circuito pulsional ao peso de ideais identificatórios da cultura. A cultura impõe restrições à agressividade, e a sexualidade é uma dessas barricadas contra os desejos de destruição, seja pensada em termos de fusão pulsional, seja como uma formação defensiva, na formulação freudiana de 1930 (p. 134). Já o sentimento inconsciente de culpa é manifestação do supereu ao retornar a violência pulsional dirigida ao outro, em agressividade contra o próprio eu. Em outras palavras, não há como a humanidade se livrar da agressividade e a tendência é sempre negar que o sujeito tenha uma inclinação para ela, fato que Freud reconheceu primeiro em si mesmo, em seus sonhos e em seu trabalho de análise pessoal. Em nossa clínica, nos ambulatórios públicos como nos consultórios privados, diante da violência urbana crescente, não cessa de aparecer o intenso sofrimento psíquico produzido, seja pelos efeitos superegoicos de contenção de condutas violentas reativas, que se manifestam, frequentemente, em sintomas pós-traumáticos, seja pelo lamento de pais que observam, impotentes, o caminho destrutivo tomado por seus familiares adolescentes e jovens.

\section{Eros e pulsão de morte}

A máxima do amor cristão é vista por Freud (1930[1929]) como uma exigência ética que não leva em conta a agressividade do ser humano, deixando-lhe a ilusão de que pode vir a ser livre da mesma: "o mandamento ideal de amar ao próximo como a si mesmo, (...) é realmente justificado pelo fato de nada mais ir tão fortemente contra a natureza original do homem" (p. 134). 
Freud (1930[1929]) se pergunta: "Qual é o sentido de um preceito enunciado com tanta solenidade, se seu cumprimento não pode ser recomendado como razoável?" (p. 131). Como qualquer um pode observar, esse preceito já está presente no Antigo Testamento, capítulo três do Levítico, ou seja, trata-se de uma antiga exigência da cultura ocidental, fato que contribui para fundamentar o argumento freudiano da origem histórica, cultural e subjetiva, isto é, psíquica, da máxima cristã.

E como tal é internalizada, como um ideal do eu, uma das barricadas erigidas contra as pulsões que ameaçam o homem a partir de dentro. Nas palavras de Freud (1930): "as criancinhas não gostam quando se fala na inata inclinação humana para a 'ruindade', a agressividade e a destrutividade, e também para a crueldade" (p. 124).

Freud declara que quando, pela primeira vez, apareceu-lhe a ideia de uma pulsão de destruição, ele mesmo levou tempo para se tornar receptivo a ela, o que cada um pode reconhecer em si mesmo, enquanto obriga a investigação a dirigir-se com mais acuidade para a definição dos conceitos, no enfrentamento com as resistências psíquicas anunciadas. Desse modo entende-se como a pergunta central da carta dirigida a Einstein ainda é um fator de inquietação subjetiva para muitos e de divergências na literatura, como se verá mais adiante.

\section{Violência e agressividade: sinônimos?}

Jurandir Freire Costa (1984), psicanalista brasileiro que tem se dedicado ao tema, no que se refere à violência postula uma diferença com a agressividade que é digna de nota. A violência constituir-se-ia em um emprego deliberado da agressividade a um objeto, ou seja, não apenas é preciso que haja uma intencionalidade para praticar a violência, mas também se pode afirmar que a violência é a agressividade utilizada para fins destrutivos.

Tudo nos leva a pensar que o convívio com a agressividade e a violência mantém-se como um desafio para os humanos, mas para nós brasileiros é urgente reconhecer a necessidade de abordá-las em sua dimensão pulsional e cultural, sem o que lidar com a agressividade constitutiva da subjetividade não ganha o relevo necessário naquilo que se distingue da violência. Ou seja, a violência disruptiva e destrutiva, é desejada e realizada por sujeitos que devem responsabilizar-se ou ser responsabilizados por ela.

E mais, o ato calculado de violência não dispensa a razão - ao contrário, solicita-a para seus fins de aniquilação. A irracionalidade da conduta violenta deve- 
-se ao fato de que a razão desconhece os móveis verdadeiros de suas intenções e finalidades. Distinta da agressividade, a violência porta a marca de um desejo. Violência é, então, o emprego desejado da agressividade, com fins destrutivos (Costa, 1984).

O mesmo não se deve dizer da agressividade, muitas vezes necessária e criativa, pois nada se constrói que não o seja sobre algo que se soterra. Ao imaginar a violência como um ato do outro, no qual não estamos incluídos, nem como agentes nem como sofrentes, alimentamos o desejo de que esta não nos atinja. Nesse sentido, pode-se dizer que se trata de mais uma ilusão que o psiquismo é capaz de sustentar e que lhe serve de consolo, ao tempo que o faz permanecer muito afastado da realidade. Modo de subjetivação alienante este, o de negar a pulsão mortífera como desejo de morte do outro e de si mesmo e suas implicações na realidade das coisas do mundo.

\section{Nas bordas da delinquência: narcisimo e midia}

Busquemos agora avançar nossa análise psicanalítica dos problemas colocados pela existência da pulsão de morte em permanente conflito com Eros, abordando mais detidamente as distinções entre agressividade, violência e tendência antissocial.

Conforme afirmamos em outro trabalho (Vilhena, 2002b), como todas as palavras demasiadamente empregadas, vemos que "violência" perdeu parte do seu sentido, ou ao menos de sua força. Termo banalizado, utilizado para descrever desde um massacre, uma chacina, até um recurso interpretativo psicanalítico, certamente não haveria consenso se buscássemos avaliar a inscrição de todas essas cenas sob o campo da violência.

Arendt (1994) aponta o caráter transgressor da violência e ressalta que o ato de violência é sempre uma forma de desobediência a uma lei, a um pacto social, a, pelo menos, um acordo. O que Arendt busca enfatizar é que não podemos abordar a questão da violência, desvinculada dos conceitos de poder ou de agressividade, sob o risco de justificarmos teses do tipo "quem domina quem".

Pode-se notar que, desde o texto de 1979, Hanna Arendt (1979) busca demonstrar que a violência destrói o poder. Enquanto a agressividade é constitutiva e se inscreve em um processo de subjetivação, na violência há um processo de destituição e anulação do outro. De acordo com ela, mesmo que o cano de uma arma produza obediência, ele jamais produzirá poder.

A agressividade, ao contrário da violência, se inscreve dentro do próprio processo de construção da subjetividade, uma vez que seu movimento ajuda a or- 
ganizar o labirinto identificatório de cada sujeito. De Freud a Lacan, com passagem por Winnicott, é possível observar a dimensão criadora da agressividade, apesar das marcadas diferenças entres os autores.

Em “Agressividade e psicanálise”, onde Lacan (1970) desenvolve algumas teses sobre essa questão, veremos como, frequentemente, a dimensão constitutiva da agressividade é enfatizada: "A agressividade se manifesta em uma experiência que é subjetiva por sua própria constituição" (p. 105).

Ou, "a agressividade é a tendência correlativa de um modo de identificação que chamaremos de narcísico e que determina a estrutura formal do eu do homem e do registro de entidades característico de seu mundo" (p.102).

De acordo com Edson de Souza (apud Vilhena, 2002b), a agressividade deve ser percebida dentro de um sistema dialógico amparado amplamente pelo registro simbólico. Isso significa que a agressividade opera quando há reconhecimento, pelo sujeito, do objeto a quem endereça sua reivindicação agressiva: "Um ato agressivo, que pode ter muitas faces e disfarces, seria simultaneamente uma resistência do Eu tentando marcar seus contornos identitários justamente quando o objeto (o outro) ameaça o seu lugar, mas também um pedido de reconhecimento e endereçamento de uma mensagem a este outro" (p. 99).

Segundo Vilhena e Maia (2003), violência, em nosso imaginário, está permanentemente associada à marginalidade, aos atos físicos de abuso (assalto, assassinato etc.), ou à ruptura de normas e leis que são respeitadas por uma determinada comunidade. Nosso mito nacional é o de uma sociedade não violenta, cordial e sem preconceitos, com episódios violentos, sempre referidos a mecanismos de exclusão social, onde nós, como agentes, não nos incluímos (p. 29).

Sendo assim, as autoras questionam sobre o que dizer da exceção que está virando a regra, da violência, da agressividade, do ato antissocial e delinquente no nosso cotidiano. Evitando deliberadamente a criticável posição de psicologizar $o$ social, que retira a responsabilidade dos que a cometem, sustentam que a psicanálise não deixa de sinalizar a responsabilidade que o sujeito deve ter por seus atos, como já vimos anteriormente.

A diferenciação entre agressividade e violência pode ser melhor entendida se for levado em consideração o narcisismo. Isto porque para a agressividade o outro ocupa um lugar que é o da autoridade, ao passo que a violência, como já foi sinalizado, desqualifica e anula o outro. Quando ocorre um aumento do narcisismo, na perspectiva da relação entre o outro e o sujeito, a violência é exacerbada.

É no reconhecimento da alteridade que podemos estabelecer os laços sociais e a solidariedade. Diferença e singularidade são pressupostos para a existência do laço social cujo traço identitário não seja o narcisismo. Em outras palavras, no registro das culturas narcísicas tudo é permitido ao sujeito que se crê o centro 
do universo. Em sua onipotência predatória o outro é apenas um objeto para usufruto de seu próprio gozo.

Como apontam Vilhena e Medeiros (2002), toda vez que ocorre uma "glamourização" da violência, pela sua espetacularização, entram em cena os mecanismos perversos que não apenas visam à aferição de lucros, posto que violência vende, como dessubjetivam o ato, transformando-o em uma encenação para o usufruto do outro. É como voyeurs que buscam situar aquele que presencia o horror. A questão que é preciso ser levantada sobre as mídias é, segundo os autores, que "noticiar os fatos é o dever ético da imprensa. Reificar o sofrimento humano é banalizar a morte e atentar contra a vida" (p. 30).

Se agora, por um lado, retomássemos a afirmação segundo a qual os atos delinquentes praticados por adolescentes - tão explorados por nossos mais variados tipos de mídia - seriam uma forma explícita de agressividade ou um tipo de ato marginal ou de loucura, por outro lado, poder-se-ia acrescentar que o "ingênuo" e "docilizado" espectador ilude-se quando somente identifica a agressividade como algo pertencente aos outros, aos delinquentes, mas não a si próprio.

Quando o outro não é reconhecido entra em cena o sentimento de desamparo: "a ampliação dos mecanismos narcísicos potencializa os mecanismos de impotência e desamparo constitutivos do sujeito, dificultando as práticas de solidariedade social" (Vilhena; Maia, 2003, p. 36-37). Por conseguinte, aparecem a intolerância, a segregação, o preconceito, o ódio àquilo que é diferente e o laço social é reduzido e tornado indesejável.

Em contraposição, a agressividade do sujeito pode ser, segundo as autoras, suportada pela família e, nesse sentido, a agressividade e a tendência antissocial podem tomar vários caminhos, dependendo do papel que esta desempenha. Ela deve ser o lugar de referência e suporte à agressividade do bebê, da criança e, no futuro, do adolescente que infringe as leis sociais. Para as autoras a violência que se vê na sociedade de hoje está relacionada a uma "falha básica" da família no que tange ao seu papel de contenedora dos impulsos agressivos. Desse modo, a tendência antissocial que existe em todos os lares pode se transformar em destrutividade, violência e delinquência (Winnicott, 1987).

Muitos adolescentes que praticam atos violentos estão respondendo ao meio que falhou com eles de uma forma intensa, o que compromete o seu futuro e acaba se tornando uma forma de "revivescência" da relação dos papéis parentais. Muitos deles procuram um sentimento de pertencimento e de inclusão, contudo, quando isto não se dá, o laço social se estabelece pelo uso abusivo da violência e da destrutividade.

Ainda que estejamos assistindo a um aumento exponencial de crimes cometidos por jovens das classes médias e altas nas grandes metrópoles, gostaríamos 
de nos deter, brevemente, sobre aqueles cujos atos são mais penalizados e ganham maior destaque, definindo, muitas vezes, políticas públicas. Jovens que, como aponta Soares (2006), vêm sendo vítimas de um verdadeiro genocídio.

A participação de crianças e jovens em comandos ligados ao narcotráfico requer uma análise que não fique restrita somente aos aspectos econômicos da questão. Entendemos que esse quadro não pode ser explicado adequadamente se não nos debruçarmos também sobre as relações sociais e familiares estabelecidas na condição de desemprego e pobreza que assolam as favelas e periferias das grandes cidades marcadas pela exclusão social e violência (Dimenstein; Zamora; Vilhena, 2005).

Nesse cenário e contexto, a coesão social pode ser afetada pela violência, pois, com frequência, o medo ou a experiência de vitimização - direta ou indireta - levam as pessoas a adotarem medidas de autoproteção que as distanciam umas das outras. Ou seja, reduzem o uso dos espaços públicos, o contato com vizinhos e parentes, vivendo o que chamamos anteriormente de confinamento.

Tal condição tem impactos importantes não só na restrição da circulação cotidiana das pessoas, mas, principalmente, por ser uma forma de controle social não institucionalizado, um dispositivo de poder, uma prática disciplinar que se exerce sobre as populações faveladas e que resultam numa sobreposição de exclusões: de classe, de gênero, de etnia e de geração. Trata-se, pois, de um confinamento geográfico, político, cultural e subjetivo que produz relações de sociabilidade muito particulares (Vilhena; Zamora, 2002).

O que Endo (2005), em seu estudo sobre a violência em São Paulo, aponta, pode ser igualmente aplicado às várias cidades brasileiras, posto que faz parte de nossa colonização e sociabilidade a exclusão das assim chamadas classes perigosas: "Na verdade, estar entre os não cidadãos numa cidade como São Paulo é aterrorizante, e suas consequências podem ser dramáticas, entre as quais figura a máxima exposição do corpo e, com, ela, a nudez da própria vida, exposta à sua eliminação" (p. 45).

Quando o ambiente, por alguma razão, fracassa em dar força ao ego incipiente, surgem as condições impositivas que possibilitam uma submissão à realidade externa, em vez do desenvolvimento da capacidade de uma abordagem criativa dos fatos. Esta é a origem de modos de subjetivação marcados pela agressividade patológica e a violência, como as condutas antissociais e a delinquência. Não há, nesses casos, a possibilidade de uso de um espaço simbólico, o espaço transicional, nos termos de Winnicott, pois este só pode ser construído com base num sentimento de confiança relacionada à fidedignidade da figura materna. 
É possível ter esperança?

Recentemente, o Brasil inteiro se mobilizou no sentido de entender que motivos cruéis levaram alguém a esganar e jogar a criança Isabella Nardoni do sexto andar de um prédio residencial em São Paulo. Como psicanalistas escutamos crianças pequenas que, ao acompanharem o caso Isabella na mídia brasileira, o relatavam demonstrando sinais de desamparo e pavor, especialmente pela suspeita, em vigor, de que seria seu próprio pai o autor de sua tragédia final.

De volta a "Mal-estar na civilização", Freud nos falará acerca da pulsão de morte como uma tendência à desestruturação, ao retorno de toda substância viva à sua pretérita condição inorgânica. A Física nos ensina que a natureza tende para o estágio de maior entropia, isto é, de maior desorganização e dispersão de energia. A pulsão de morte pode ser corretamente entendida como a extensão do processo entrópico universal para dentro do psiquismo humano.

É por sermos então seres tão frágeis, tão autodestrutivos, e dotados de um equilíbrio apenas sutil, que precisamos resistir ao desejo cotidiano de atentarmos contra a vida. Disto também sabia Freud (1933[1932]), ao apontar a necessidade de uma instância fundada no direito e nas leis.

Novamente a pulsão de morte está postulada aqui como um desejo de morte, e pode ajudar a mostrar a coerência da leitura de Laplanche (1985) sobre a pulsão de morte freudiana como o desligamento da libido do objeto, seu desinvestimento. A renúncia ao laço social, o desinvestimento no objeto, o silenciamento do sujeito, as melancolias e depressões, o esvaziamento do eu, o sentimento de desamparo, ou seja, toda produção de subjetividade resultante da violência mortífera da pulsão de morte, que nesste sentido não está sendo postulada como um impulso que movimenta a ação destrutiva, diferentemente da leitura de Klein e dos kleinianos (Hinshelwood, 1992, p. 447), pode demonstrar que há um movimento psíquico que cursa na direção do inorgânico. Talvez tenhamos que postular então um modo de produção de dessubjetivação em curso, pulsional e mortífero.

Frequentemente associamos o ato delinquente à pobreza, criminalidade e carência material. Ainda que estejamos muitas vezes bem-intencionados, redunda desse tipo de raciocínio uma ligação da pobreza com a ilegalidade, quando não com a barbárie. Falar da agressividade da infância, de crianças cada vez menores assusta, mas é preciso indagar: qual é o lugar da trama social nessa criança que agride? Qual o endereçamento dessa violência? Aonde buscar uma compreensão da conduta cada vez mais violenta de tantas crianças e jovens?

Essa territorialização do crime e da violência em favelas e periferias urbanas pode ser compreendida como a "atualização dos campos de concentração e de extermínio", na medida em que há uma identificação pública dos inimigos so- 
ciais e sua delimitação em espaços localizados, em fronteiras demarcadas, promovendo sua desqualificação e estigmatização, acentuando a vigilância e o controle (Wacquant, 2001, p. 14).

As comunidades de baixa renda são, assim, reduzidas a locais de perigo, crimes e drogas, e, além disso, as crianças e jovens são vistos apenas como perigosos, ao invés de serem abordadas em termos do seu potencial.

Sociedades complexas e extremamente desiguais frequentemente promovem não somente os socialmente excluídos, mas também os "não afiliados", os desenraizados. Em tais situações, esses grupos podem ser descritos geográfica e psicologicamente como estando nos subúrbios da cidadania. Sem essa dimensão de afiliação o processo de afirmação identitária pode ficar comprometido ou ancorado em valores que não os da coletividade, podendo inclusive ser fonte de sofrimento e loucura. Em tais situações nós poderíamos pensar na violência como uma marca que permite ao sujeito emergir de um lugar não escolhido por ele, à procura de afiliação e reconhecimento - um lugar em uma pólis que o rejeitou (Vilhena, 2002a).

Por isto enfatizamos que a questão da delinquência não pode ser circunscrita a uma classe, nem reduzida a uma patologia social. $\mathrm{O}$ ato delinquente é, muitas vezes, uma busca de filiação, de reconhecimento - ato fadado ao fracasso - uma vez que a busca em questão é por um objeto simbólico e não por um objeto real e concreto. Mas trata-se, se isto se pode afirmar, de uma massiva produção de subjetividade violenta em escala nacional caracterizando o cenário em que o personagem trágico é a juventude brasileira, e o enredo, seu genocídio. Estar com o coro ou sentar na plateia desse teatro de horror? Eis a questão que se coloca para a brasilidade.

Portanto, se até aqui não se encontra razão para eximir a agressividade da subjetividade, o que examinamos no caso brasileiro, é preciso que se admita a necessidade de se lidar e conviver com o mal-estar que disso resulta, ao tempo em que se combate o que de violento, humilhante e degradante há nele.

No final de "Por que a guerra?" (1933[1932]), Freud afirma que o fortalecimento da vida intelectual pode ajudar o homem a não expressar sua agressividade através dos conflitos bélicos, apesar de afirmar a impossibilidade de eliminar por completo a pulsão agressiva do homem. De acordo com Freud: Dentre as características psicológicas da civilização, duas aparecem como as mais importantes: o fortalecimento do intelecto, que está começando a governar a vida pulsional, e a internalização das pulsões agressivas com todas as suas consequentes vantagens e perigos (p. 207).

Estamos aqui, como se sabe, no campo de esperança que ele compartilha com grandes pensadores da nossa cultura, que postularam a razão como instru- 
mento humano disponível para todos, no que se refere à ética que o responsabiliza por seus atos.

Para Winnicott (1971) isto só será possível enquanto a criança tiver esperança. Esperança não só de ver suas necessidades atendidas, mas, também, de poder contar com o outro, de poder ser amada, de poder construir projetos de vida.

Nessa direção é que propusemos, neste artigo, refletir acerca do que leva alguém a se autorizar a agir de forma violenta com nossas crianças e adolescentes, na prática da violência doméstica ou na pólis.

Depois de Freud não vale mais se ater a argumentos que tornam a violência algo que diz respeito ao outro, ao estrangeiro, ao excluído, mas é à própria sociedade brasileira que se dirige a questão, ainda que a dinâmica do conflito entre o pulsional e a cultura, enquanto processo inconsciente, exija mais do que a racionalidade nos pode oferecer.

A tese freudiana, que aqui apresentamos em brevíssimas linhas, postula que a vida psíquica e social do homem estará sempre permeada pelo conflito entre Eros e pulsão de morte. Resta desejar que a humanidade possa mais e mais refleti-la e alcançar a grandeza de se responsabilizar pelas escolhas que puder fazer.

Caso contrário estaremos de volta à barbárie, em que irmãos matam irmãos porque não podem ser vistos no espaço público. Quando não se vê algo, esse algo não existe - "ser é ser percebido". Mas ser é, antes de tudo, ser para alguém. Ver e ser visto são duas faces da mesma moeda nos encontros humanos. O sujeito só acontece decisivamente a partir do olhar do outro. Somente assim é que ele pode, realmente, assumir sua própria existência.

\section{Referências}

Arendt, H. (1973). Da violência. In: Crises da República. São Paulo: Perspectiva, 1991.

. As origens do totalitarismo. Totalitarismo, o paroxismo do poder. Rio de Janeiro: Documentário, 1973.

. A condição humana. 5. ed. Rio de Janeiro: Forense Universitária, 1991.

. Sobre a violência. Rio de Janeiro: Relume-Dumará, 1994.

Benjamin, W. Obras escolhidas III - Charles Baudelaire, um lírico no auge do capitalismo. Trad. de José Carlos Martins Borba e Hemerson Alves Baptista. São Paulo: Brasiliense, 1978.

Rev. Latinoam. Psicopat. Fund., São Paulo, v. 12, n. 4, p. 677-697, dezembro 2009 
Bignotto, N. As fronteiras da ética. In: Ética. São Paulo: Companhia das Letras, 1992. Costa, J. F. Violência e psicanálise. Rio de Janeiro: Record, 1984.

Dimenstein, M.; Zamora, M.H.; Vilhena, J. Sobre a vida dos jovens nas favelas cariocas. Revista do Departamento de Psicologia, Niterói, v. 16, n. 1, p. 24-39, 2005.

Elias, N. O processo civilizador II. Rio de Janeiro: Jorge Zahar, 1994.

Endo, P. A violência no coração da cidade. São Paulo: Escuta/Fapesp, 2005.

Freud, S. (1913). Totem e tabu. In: Edição Standard Brasileira das Obras Psicológicas Completas de Sigmund Freud. Rio de Janeiro: Imago, 2002. v. XIII.

. (1930). O mal-estar na civilização. In: Edição Standard Brasileira das Obras Psicológicas Completas de Sigmund Freud. Rio de Janeiro: Imago, 2002. v. XXI. . (1933[1932]). Por que a guerra? In: Edição Standard Brasileira das Obras Psicológicas Completas de Sigmund Freud. Rio de Janeiro: Imago, 2002. v. XXII. Hinshelwood, R.D. Dicionário do pensamento kleiniano. Porto Alegre: Artes Médicas, 1992.

Lacan, J. (1969-1970). O seminário. Livro 17. O avesso da psicanálise. Rio de Janeiro: Jorge Zahar, 1992.

Laplanche, J. Vida e morte em psicanálise. Porto Alegre: Artes Médicas, 1985.

Machiavelle, N. The Prince And The Discourses. New York: Random House, 1950.

Neder, G. Cultura, poder e violência. Revista Latinoamericana de Psicopatologia Fundamental, São Paulo, v. 12, n. 1, p. 17-30, mar. 2009.

PInHeiro, P.S. Escritos indignados. São Paulo: Brasiliense, 1984.

Poulantzas, N. O Estado, o Poder, o Socialismo. Rio de Janeiro: Paz e Terra, 1981.

SoARes, L. E. Estamos cometendo um genocídio juvenil. Agencia Notisa. Jornalismo Científico. Recebido por e-mail em 25/8/2006.

SousA, E. L. A. A eloquência da agressividade e o silêncio da violência. s/d. (cópia mimeo).

Vilhena, J. Da cidade onde vivemos a uma clínica do território. Lugar e produção de subjetividade. Pulsional Revista de Psicanálise, São Paulo, ano XV, n. 163 , p. 48-54, 2002a.

. A arquitetura da violência. Reflexões acerca da violência e do poder na cultura. Cadernos de Psicanálise, Rio de Janeiro, v. 18, n. 21, p. 181-200, 2002b. Vilhena, J.; Zamora, M. H. Being a Child in a Brazilian Slum. Clio's Psyche. Psychohistory Forum. The Psychohistory Forum, New Jersey, v. 9, n. 1, p. 16-18, 2002. 
Vilhena, J.; Maia, M. V. Violência e agressividade. Notas sobre a tendência antissocial na cultura contemporânea. Revista Mal-Estar e Subjetividade, Fortaleza, v. II, n. 2, p. 27-58, 2003.

Vilhena, J.; Medeiros, S. Mídia e perversão. Ciência Hoje, Rio de Janeiro, v. 31, n. 183 , p. 28-31, 2002.

Wacquant, L. Os condenados da cidade: estudos sobre marginalidade avançada. Rio de Janeiro: Revan/Fase, 2001.

Weber, M. A ética protestante e o "espírito” do Capitalismo. São Paulo: Companhia das Letras, 2004.

Winnicott, D. Privação e delinquência. São Paulo: Martins Fontes,1987. . A criança e seu mundo. Rio de Janeiro: Zahar, 1971.

. Objetos transicionais e fenômenos transicionais. In: $O$ brincar e a realidade.

Rio de Janeiro: Imago, 1975. p. 25-38.

\section{Resumos}

(Quién tiene miedo del lobo malo? Juventud, agresividad y violencia)

Este estudio analiza la dinámica de la agresión y la violencia y el papel que desempeña la cultura brasileña con respecto a nuestra juventud. Hemos comenzado nuestro trabajo sobre la base de Freud y su concepto de la violencia. En la teoría de Winnicott, señalamos las diferencias entre la agresividad y la tendencia social que puede finalmente dar lugar a la violencia destructiva y a la delincuencia. Teniendo en cuenta que la "madre del medio ambiente" está anclada en la cultura, para finalizar se discute el lugar designado a estos jóvenes en nuestra sociedad.

Palabras clave: Agresión, violencia, jóvenes, exclusión social, tendencia antisocial

(Qui a peur du grand méchant loup? Jeunesse, agressivité et violence)

Cette étude examine la dynamique de l'agression et de la violence et le rôle de la culture brésilienne en ce qui concerne ses jeunes. Ce travail est basé sur Freud et son concept de la violence, ainsi que sur la théorie de Winnicott. Il met en relief les différences entre l'agressivité et la tendance anti-sociale qui peut déboucher sur la violence destructrice de la délinquance. Partant de l'hypothèse que la "mère environnement" est ancrée dans la culture, il discute la place de ces jeunes dans la société brésilienne.

Mots clés: Agression, violence, jeunes, exclusion sociale, tendance anti-sociale 
(Who's afraid of the big bad wolf? Youth, aggressiveness and violence)

This study discusses the dynamics of aggressiveness and violence, and the role of Brazilian culture regarding its youth. The article is based largely on Freud's concept of violence. Based on Winnicott's theory, we point out the differences between aggressiveness and the anti-social trend that may ultimately result in destructive violence and delinquency. Considering that the "environmental mother" is anchored in culture, we discuss the place given to these young people in our society.

Key words: Aggressiveness, violence, youth, social exclusion, anti-social tendencies

Citação/Citation: Moreira, A.C.G. et al. Quem tem medo do lobo mau? Juventude, agressividade e violência. Revista Latinoamericana de Psicopatologia Fundamental, São Paulo, v. 12, n. 4, p. 677-697, dez. 2009.

Editor do artigo/Editor: Prof. Dr. Manoel Tosta Berlinck.

Recebido/Received: 28.8.2008 / 8.28.2008 Aceito/Accepted: 5.4.2009 / 4.5.2009

Copyright: @ $\odot 2009$ Associação Universitária de Pesquisa em Psicopatologia Fundamental/ University Association for Research in Fundamental Psychopathology. Este é um artigo de livre acesso, que permite uso irrestrito, distribuição e reprodução em qualquer meio, desde que $o$ autor e a fonte sejam citados/This is an open-access article, which permits unrestricted use, distribution, and reproduction in any medium, provided the original author and source are credited.

Financiamento/Funding: Esta pesquisa foi financiada pela CAPES - Coordenação de Aperfeiçoamento de Pessoal de Nível Superior (São Paulo, SP, Brasil) / This research has been funded by the "CAPES - Coordenação de Aperfeiçoamento de Pessoal de Nível Superior " (São Paulo, SP, Brazil).

Conflito de interesses: Os autores declaram que não há conflito de interesses/The authors declare that has no conflict of interest.

\section{Ana Cleide Guedes Moreira}

Psicanalista; doutora em Psicologia pela Pontifícia Universidade Católica de São Paulo - PUC-SP (São Paulo, SP, Brasil);vice coordenadora do Programa de Pós-Graduação em Psicologia da Universidade Federal do Pará - UFPA (Belém, PA, Brasil); diretora do Laboratório de Psicanálise e Psicopatologia Fundamental da Universidade Federal do Pará - UFPA (Belém, PA, Brasil); membro da Associação Universitária de Pesquisa em Psicopatologia Fundamental (São Paulo, SP, Brasil); bolsista da Coordenação de Aperfeiçoamento de Pessoal de Nível Superior - CAPES, através do Programa Nacional de Cooperação Acadêmica - PROCAD (Brasília, DF, Brasil); pesquisadora associada do Laboratório Interdisciplinar de Pesquisa e Intervenção Social - LIPIS/PUC-Rio (Rio de Janeiro, RJ, Brasil). 
Rua Augusto Corrêa, n. 1

66075-900 Belém, PA, Brasil

e-mail: acleide@uol.com.br

\section{Junia de Vilhena}

Psicanalista; professora do Depto. de Psicologia da Pontifícia Universidade Católica do Rio de Janeiro - PUC-Rio (Rio de Janeiro, RJ, Brasil); coordenadora do Laboratório Interdisciplinar de Pesquisa e Intervenção Social - LIPIS da PUC-Rio; bolsista da Coordenação de Aperfeiçoamento de Pessoal de Nível Superior - CAPES (Brasília, DF, Brasil), membro da Associação Universitária de Pesquisa em Psicopatologia Fundamental (São Paulo, SP, Brasil); pesquisadora correspondente do Centre de Recherches Psychanalyse et Médecine - CRPM - Pandora.Université Denis-Diderot Paris 7 (Paris, França).

Rua Tenente Marcio Pinto, 183 - Gávea

22451-290 Rio de Janeiro, RJ, Brasil

e-mailvilhena@puc-rio.br / lipis@puc-rio.br / www:juniadevilhena.com.br

\section{Alexandre Theo de Almeida Cruz}

Mestre em Psicologia pela Universidade Federal do Pará - UFPA (Belém, PA, Brasil); psicólogo do Ministério Público do Pará (Belém, PA, Brasil); professor de Psicologia Jurídica e diretor do Centro de Ciências Biológicas e da Saúde da Universidade da Amazônia - UNAMA (Manaus, AM, Brasil); pesquisador associado do Laboratório Interdisciplinar de Pesquisa e Intervenção Social - LIPIS/PUC-Rio (Rio de Janeiro, RJ, Brasil).

Rua dos Mundurucus, 4309 - São Braz

66073-000 Belém, PA, Brasil

e-mail: theo.cruz@hotmail.com

\section{Joana de Vilhena Novaes}

Psicanalista; pós-doutoranda em Clínica Médica pela Universidade do Estado do Rio de Janeiro - UERJ (Rio de Janeiro, RJ, Brasil); pós-doutora em Psicologia Social pela mesma universidade; doutora em Psicologia Clínica pela Pontifícia Universidade Católica do Rio de Janeiro - PUC-Rio (Rio de Janeiro, RJ, Brasil); pesquisadora do Laboratório de Pesquisas Clínica e Experimental em Biologia Vascular (Bio-Vasc) da Universidade do Estado do Rio de Janeiro - UERJ; coordenadora do Núcleo de Doenças da Beleza da Pontifícia Universidade Católica do Rio de Janeiro - PUC-Rio; pesquisadora e psicoterapeuta do Laboratório Interdisciplinar de Pesquisa e Intervenção Social - LIPIS/PUC-Rio (Rio de Janeiro, RJ, Brasil); pesquisadora correspondente do Centre de Recherches Psychanalyse et Médecine - Université Denis-Diderot Paris 7 CRPM-Pandora (Paris, França); bolsista da Fundação de Amparo a Pesquisa do Estado do Rio de Janeiro - FAPERJ (Rio de Janeiro, RJ, Brasil).

Av. Ataulfo de Paiva, 135/613 - Leblon

22440-901 Rio de Janeiro, RJ, Brasil

e-mail: joananovaes@terra.com.br / www.joanadevilhenanovaes.com.br 